\title{
Exopeptidase Degradation for the Analysis of Phosphorylation Site in a Mono-phosphorylated Peptide with Matrix-assisted Laser Desorption/Ionization Mass Spectrometry
}

\author{
Nariyasu Mano, ${ }^{* \dagger}$ Setsuko IIJIMA,* Kie KaSUga,* and Junichi Goto**** \\ * Graduate School of Pharmaceutical Sciences, Tohoku University, Aobayama, Aoba, Sendai 980-8578, Japan \\ **Department of Pharmaceutical Sciences, Tohoku University Hospital, 1-1 Seiryo-machi, Aoba, \\ Sendai 980-8574, Japan
}

\begin{abstract}
The utility of matrix-assisted laser desorption/ionization time-of-flight mass spectrometry (MALDI-TOFMS) coupled with a peptide ladder sequencing method employing exopeptidase degradation for the analysis of phosphorylation site in a mono-phosphorylated peptide is investigated. MALDI-TOFMS analysis of time-dependent exopeptidase digestion using carboxypeptidase $\mathrm{W}$ and aminopeptidase $\mathrm{M}$ of the mono-phosphorylated 33-48 fragment isolated from a $\beta$-casein tryptic digestion mixture allowed for the sequencing analysis from both the $\mathrm{C}$-terminus and $\mathrm{N}$-terminus. Negative ion detection MALDI-TOFMS made it possible to clearly measure the peptide ladder of mono-phosphorylated peptide by the strong negative charge localized at the phosphoric acid group. Since exopeptidase activity was suppressed by the existence of a phosphorylated amino acid residue, the termination exopeptidase degradation therefore suggested the existence of a phosphorylated amino acid residue at that site. This peptide ladder sequencing method using exopeptidases was effective for the identification of the site of a phosphorylated amino acid residue by a simple MALDI-TOFMS analysis in the negative ion detection mode.
\end{abstract}

(Received September 22, 2003; Accepted October 10, 2003)

\section{Introduction}

Phosphorylation of serine, threonine and/or tyrosine residues is one of the most common and important post-translational modifications of proteins for regulation of many cellular processes such as signal transduction, gene expression, cell cycle and apoptosis. The analysis of phosphorylation sites is therefore very important in understanding the role of the modifications in intracellular signaling. Mass spectrometry is a powerful tool for identifying phosphorylation sites with high sensitivity and throughput. ${ }^{1-5}$ Tandem mass spectrometry is the most useful for identifying a phosphorylation site in the phosphopeptide, and is applied for phosphorylated peptides generally separated from other peptides by HPLC or more selective enrichment procedure such as an immobilized metal affinity chromatography ${ }^{6-10}$ and an immunoprecipitation using anti-phosphorylated amino acid residue antibodies. ${ }^{11,12}$ The fragmentation of $\mathrm{HPO}_{3}$ or $\mathrm{H}_{3} \mathrm{PO}_{4}$ from a phosphorylated peptide is more frequent than backbone clevages, and fragment ions containing phosphates often provide a pair of peaks with a mass shift of $80 \mathrm{Da}$ or $98 \mathrm{Da}$ as y-type or b-type ions. However, a phosphopeptides with strong negative charges are often difficult to detect directly with the positive ion detection mode under general conditions. Janek et al. have compared the detection sensitivity of positive and negative ions of synthesized phosphopeptides, and they found that phosphopeptides, which

† To whom correspondence should be addressed.

E-mail: n-mano@mail.pharm.tohoku.ac.jp have a low ionization efficiency in the positive ion mode, gave relatively sensitive anions in comparison with other peptides in the negative ion mode. ${ }^{13}$ Furthermore, phosphopeptides produced by the enzymatic digestion of model proteins can be detected easily in peptide mass fingerprints obtained in the negative ion mode.

Several methods for peptide sequencing determination have been developed except for using tandem mass spectrometry. Protein ladder sequencing reported by Chait et al. is an approach to $\mathrm{N}$-terminal protein sequencing combined with a multiple steps of Edman degradation chemistry using a MALDI-TOFMS determination. ${ }^{14}$ Although this method can identify $\mathrm{N}$-terminal sequence with only one mass mapping by MALDI-TOFMS, it is limited to the N-terminus of peptides. Sequence information from the C-terminus of peptide has been obtained by chemical degradation methods, ${ }^{15,16}$ but those methods have been difficult on the operation. A different approach to chemical sequencing uses enzymatic reactions. Several carboxypeptidases have been demonstrated to be attractive to analyze the C-terminal sequencing by concentration-dependent digestion ${ }^{17}$ and time-dependent digestion. ${ }^{18,19}$

In the present study, the peptide ladder sequencing strategy employing exopeptidase digestion coupled with MALDITOFMS has been applied to the analysis of phosphorylation site in a mono-phosphorylated peptide. The authors used the 33-48 fragment (FQpSEEQQQTEDELQDK) isolated from $\beta$-casein tryptic digest as a model mono-phosphorylated peptide. 


\section{Experimental}

\section{Materials}

Alkaline phosphatase, $\alpha$-cyano-4-hydroxycinnamic acid ( $\alpha$ CHCA) and $\beta$-casein were purchased from SIGMA Chemical Co., (St. Louis, MO, USA). Sequence-grade modified trypsin was obtained from Promega (Madison, WI, USA). Carboxypeptidase W was obtained from Seikagaku Co. (Tokyo, Japan) and aminopeptidase $\mathrm{M}$ was purchased from Roche Diagnostics Co. (Tokyo). Distilled and ion-exchanged water was prepared by CPW-100 ULTRA PURE WATER SYSTEM (ADVANTEC TOYO Co., Tokyo), and other reagents and solvents were of HPLC grade.

\section{Apparatus}

MALDI-TOFMS analysis was performed using Voyager RP (Applied Biosystems, Framingham, MA, USA) and AXIMACFR (Shimadzu, Kyoto, Japan) equipped with an $\mathrm{N}_{2}$ laser (337 $\mathrm{nm})$ under the linear mode. The accelerating and grid voltages were $25 \mathrm{kV}$ and $18 \mathrm{kV}$, respectively. The matrix solution used in both positive and negative ion modes was a fresh solution of $\alpha$-CHCA in acetonitrile containing $0.1 \%$ TFA at a concentration of $10 \mathrm{mg} / \mathrm{mL}$. Peptide samples in a water/acetonitrile mixture $(3: 7, \mathrm{v} / \mathrm{v})$ containing $0.1 \%$ TFA were mixed with the matrix solution at a ratio of $1: 1$, and a $1-\mu \mathrm{L}$ aliquot of the mixture was applied to the sample plate. Spectra were calibrated internally or externally using average $[\mathrm{M}+\mathrm{H}]^{+}$or $[\mathrm{M}-\mathrm{H}]^{-}$ions of two peptide standards, angiotensin I and the ACTH 7-38 fragment (American Peptide Company, Inc., Sunnyvale, CA, USA), which were included in the matrix solution.

A Nanospace SI-1 solvent delivery system (Shiseido, Tokyo) equipped with a UV detector set at $215 \mathrm{~nm}$ was used to the purification of the phosphorylated 33-48 fragment of bovine $\beta$ casein and time course of the enzymatic degradation using exopeptidases. Liquid chromatographic separation was performed on a Jupiter $5 \mathrm{uC} 18300 \AA$ ( $5 \mu \mathrm{m}, 2.0 \mathrm{~mm}$ i.d. $\times 150$ $\mathrm{mm}$, Phenomex, Torrance, CA, USA) at a flow rate of 200 $\mu \mathrm{L} / \mathrm{min}$ with a 10 to $60 \%$ linear gradient of mobile phase B over 30 min. Mobile phase A was water/acetonitrile (9:1) containing $0.1 \%$ TFA and mobile phase B was water/acetonitrile (1:9) containing $0.1 \%$ TFA.

\section{Preparation of mono-phosphorylated peptide fragment}

$\beta$-Casein $(4 \mathrm{nmol})$ was dissolved in $100 \mu \mathrm{L}$ of $50 \mathrm{mM}$ ammonium bicarbonate, and $1.6 \mu \mathrm{g}$ of sequence-grade modified trypsin in $8 \mu \mathrm{L}$ of $50 \mathrm{mM}$ ammonium bicarbonate. After incubation overnight at $37^{\circ} \mathrm{C}$, tryptic peptide fragments were separated by HPLC, and the mono-phosphorylated peptide fragment $(33$ - 48) was isolated, whose molecular weight was measured by both the positive and negative MALDI-TOFMS. Dephosphorylated 33-48 fragment was prepared as follows. $\beta$ Casein (4 nmol) was dissolved in $100 \mu \mathrm{L}$ of $50 \mathrm{mM}$ ammonium bicarbonate, and $10 \mu \mathrm{L}$ of alkaline phosphatase solution (1 $\mathrm{U} / \mu \mathrm{L})$. After incubation overnight at $30^{\circ} \mathrm{C}$, tryptic digestion was carried out by the same manner as described above. And the fraction was measured by the positive MALDI-TOFMS.

\section{Ladder sequencing procedure using exopeptidase}

The phosphopeptide or dephosphorylated peptide purified by HPLC was cleaved enzymatically at every amino acid residue according to the following procedure. To the target peptide (10 pmol) was dissolved in $15 \mu \mathrm{L}$ of $50 \mathrm{mM}$ ammonium acetate buffer ( $\mathrm{pH}$ 4.0), $1.2 \mu \mathrm{g}$ of carboxypeptidase W (substrate/enzyme ratio: ca. 20/1) was added. To prepare the C- terminal peptide ladder, $3-\mu \mathrm{L}$ aliquots of the reaction mixture were withdrawn and each mixed with $3 \mu \mathrm{L}$ of $0.2 \%$ TFA to terminate digestion after incubation at $37^{\circ} \mathrm{C}$ for various amounts of time. Each sample, differing in their incubation times, was analyzed by MALDI-TOFMS. The N-terminal peptide ladder was prepared as follows. The peptide $(10 \mathrm{pmol})$ was dissolved in $12 \mu \mathrm{L}$ of $50 \mathrm{mM}$ Tris- $\mathrm{HCl}$ buffer ( $\mathrm{pH} 7.5)$ containing $1 \mathrm{mM}$ $\mathrm{MgCl}_{2}$, to which was added $64 \mu \mathrm{L}$ of aminopeptidase $\mathrm{M}$ solution $(20 \mathrm{unit} / 1 \mathrm{~mL})$. After incubation at $37^{\circ} \mathrm{C}$ for various amounts of times, $11-\mu \mathrm{L}$ aliquots were mixed with $8 \mu \mathrm{L}$ of $0.2 \%$ TFA and purified using ZipTipC18 before analysis by MALDI-TOFMS.

\section{Result and Discussion}

\section{Isolation of phosphopeptides produced by tryptic digestion}

The detection sensitivity of phosphopeptides is different from that of other peptides when MALDI mass spectrometry in positive and negative ion modes were used, ${ }^{13}$ because every peptide fragment produced by enzymatic cleavage has a different charge and set of physicochemical properties. Peptide mapping by HPLC monitored at $210-220 \mathrm{~nm}$ based on the UV absorbance of the peptide backbone can detect phosphopeptides with similar sensitivity as it can other peptide fragments. Comparison of HPLC peptide maps obtained by enzymatic digestion with and without alkaline phosphatase treatment can identify phosphopeptides in a complex peptide mixture. Figure 1 shows peptide maps obtained by tryptic digestion of $\beta$-casein with (upper chromatogram) or without (lower chromatogram) alkaline phosphatase cleavage. In the dephosphorylated peptide map, one peak at a retention time of 10 min disappeared from the HPLC chromatogram when compared with the native peptide map, converging to the next peak at a retention time of $10.4 \mathrm{~min}$. In the positive ion MALDI mass measurement, the 10-min peak gave a protonated peptide molecule at $\mathrm{m} / \mathrm{z} 2063$ corresponding to the mono-phosphorylated 33-48 fragment, and the 10.4-min peak gave a mass peak at $\mathrm{m} / z .1983$ corresponding to the dephosphorylated peptide (data not shown). And the 10min peak gave also a deprotonated peptide molecule at $\mathrm{m} / \mathrm{z}, 2061$ with highly sensitivity in the negative ion detection mode. In addition, to confirm the relationship between those two peaks, the peak corresponding to the protonated molecule at $\mathrm{m} / \mathrm{z}, 2063$ was treated by alkaline phosphatase, giving a new peptide ion at $\mathrm{m} / \mathrm{z}$ 1983, which is consistent with the dephosphorylated 33-48 peptide (data not shown). These results suggest that the 10- and 10.4-min peaks are the mono-phosphorylated 33-48 fragment and its dephosphorylated counterpart, respectively. Finally, comparison of the peak intensities on the HPLC chromatogram reveals that the 33-48 fragment of $\beta$-casein is partially monophosphorylated at a ratio of about 1:1.

\section{Peptide ladder sequencing using exopeptidases}

The isolated mono-phosphorylated 33-48 fragment was timedependently digested to form $\mathrm{C}$ - and $\mathrm{N}$-terminal peptide ladders using carboxypeptidase $\mathrm{W}$ and aminopeptidase $\mathrm{M}$, respectively. The phosphorylated group in this peptide was sufficiently stable during digestion by aminopeptidase $\mathrm{M}$ and carboxypeptidase $\mathrm{W}$. The C-terminal ladder was obtained time-dependently using incubation times from 0 to $300 \mathrm{~min}$ as shown in Fig. 2(A). The peptide including a lysine residue, gave an intense peak, while the peak intensities of other peptides were lower because of the strong negative charge of the phosphate group. When the same sample is measured in the negative ion mode, the peak intensity of each of the ladder peptides was higher, simplifying the 


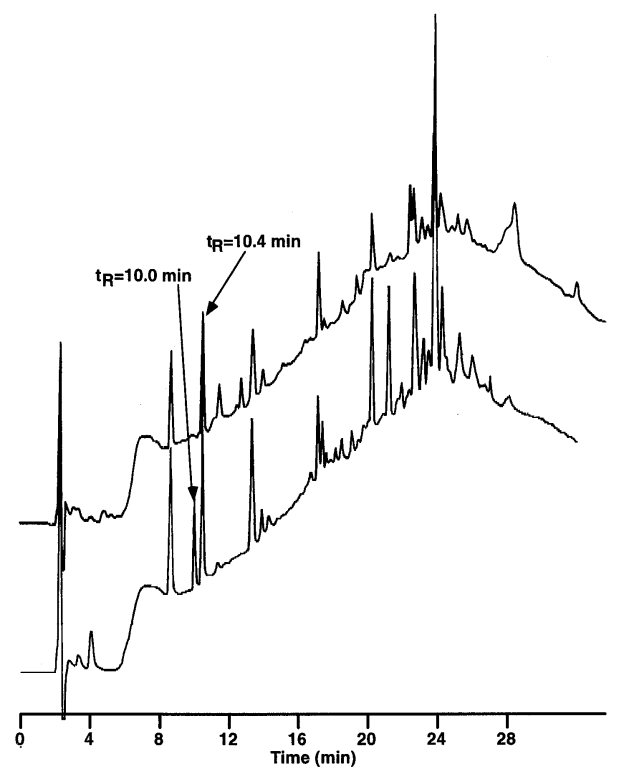

Fig. 1 HPLC peptide-mapping of $\beta$-casein tryptic digest. Lower chromatogram, $\beta$-casein tryptic digest; upper chromatogram, $\beta$-casein tryptic digest after dephosphorylation using alkaline phosphatase.

peptide ladder sequencing as shown in Fig. 2(B). Although the lack of peaks corresponding to FQpSEEQQQTEDE and FQpSEEQQQTEDELQ was observed in the positive ion mode, both peaks were barely detected in the negative ion mode. The mono-phosphorylated 33-48 fragment used for this analysis included two possible phosphorylated amino acid residues, Ser 35 and Thr 41. The results of Figs. 2(A) and (B) indicate that there may be no phosphate group at the latter location. The use of aminopeptidase $\mathrm{M}$ as an exopeptidase produces an $\mathrm{N}$ terminal peptide ladder. ${ }^{19}$ However, the enzymatic reaction was blocked N-terminal to the serine residue, which may be phosphorylated on its side-chain hydroxyl group (Fig. 2(C)). The same result was obtained for the N-terminal peptide ladder in negative ion mode, although the detection sensitivity of the phosphorylated peptide ladder was relatively higher than in the positive ion mode, as shown in Fig. 2(D). This phosphorylated amino acid residue is known to resist cleavage by aminopeptidase M, carboxypeptidase W and other exopeptidases. $^{20}$ These results suggest that the phosphorylated amino acid residue is Ser 35, agreeing with previous reports on the database.

To investigate the resistance of phosphorylated amino acid residues to exopeptidase treatments, the dephosphorylated 3348 fragment was subjected to peptide ladder sequencing using both carboxypeptidase W and aminopeptidase M. Figure 3(A) illustrates the C-terminal peptide ladder sequencing of the dephosphorylated peptide with an $\mathrm{m} / \mathrm{z}$ 1982. Although low intense peaks exist within the ladder, the peaks corresponding to the dephosphorylated peptide are detected in the range from $\mathrm{Thr}$ 41 to Lys 48. On the other hand, as shown in Fig. 3(B), the Nterminal peptide ladder clarified the site of the phosphorylated amino acid residue, because the dephosphorylated peptide can produce the $\mathrm{N}$-terminal peptide ladder in the range from Phe 33 to Glu 37 in a shorter reaction time than in Figs. 2(C) and (D). The results suggest that the phosphorylated amino acid residue resists exopeptidase treatment in the production of the peptide ladder and that Ser 35 is partially phosphorylated in the native $\beta$-casein molecule.
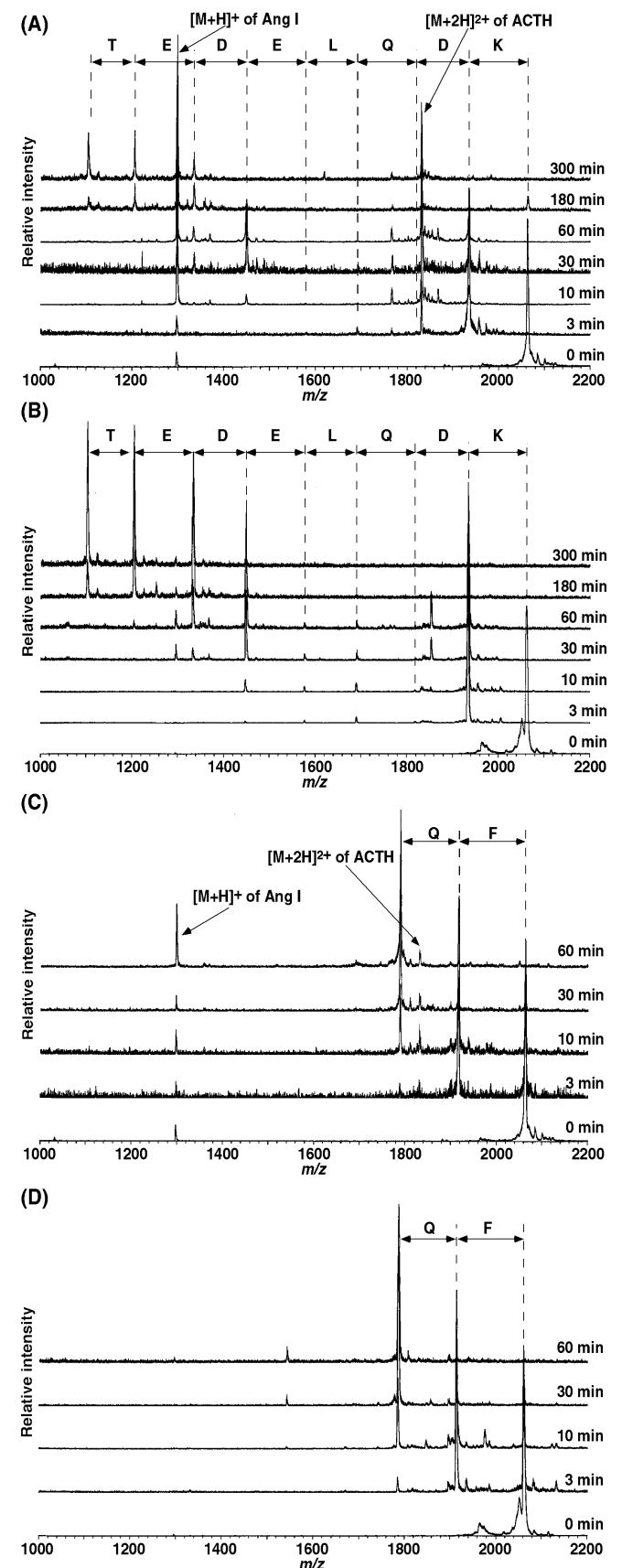

Fig. 2 Enzymatic peptide ladder sequencing of the monophosphorylated 33-48 fragment obtained from $\beta$-casein tryptic digest.

(A) C-terminal peptide ladder sequencing in the positive ion mode;

(B) C-terminal peptide ladder sequencing in the negative ion mode;

(C) N-terminal peptide ladder sequencing in the positive ion mode;

(D) $\mathrm{N}$-terminal peptide ladder sequencing in the negative ion mode.

In conclusion, peptide ladder sequencing using aminopeptidase $\mathrm{M}$ and carboxypeptidase $\mathrm{W}$ is a very simple method, requiring only MALDI-TOFMS coupled with an enzymatic reaction and not any special instruments such as MS/MS. Negative ion detection is also useful for phosphopeptide analysis, and helps to simplify amino acid sequence analysis. This enzymatic peptide ladder sequencing method described in this study will be useful for characterization of other post-translational modifications such as a glycosylation. 

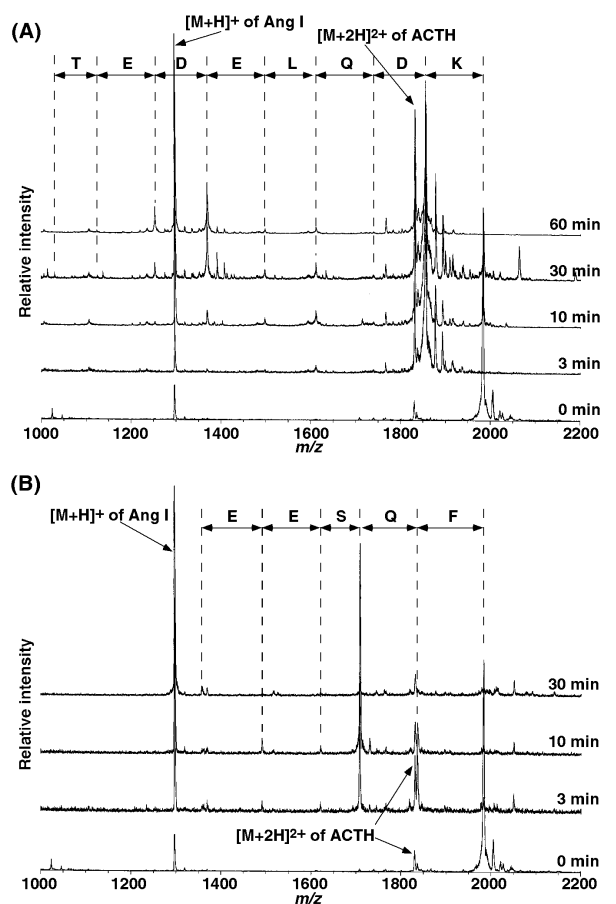

Fig. 3 Enzymatic peptide ladder sequencing of the dephosphorylated 33-48 fragment by the positive MALDI-TOFMS (A) C-terminal peptide ladder sequencing; (B) $\mathrm{N}$-terminal peptide ladder sequencing.

\section{Acknowledgements}

This work was supported in part by a grant from the Ministry of Education, Culture, Sports, Science and Technology, a grant for Research on Health Sciences focusing on Drug Innovation from the Japan Health Sciences Foundation and a Grant-in-Aid for Cancer Research from the Ministry of Health, Labor and Welfare.

\section{References}

1. A. Tholey, J. Reed, and W. D. Lehman, J. Mass Spectrom., 1999, 34, 117.

2. H. Steen, B. Küster, M. Fernandez, A. Pandey, and M. Mann, Anal. Chem., 2001, 73, 1440.

3. H. Steen and B. Küster, and M. Mann, J. Mass Spectrom., 2001, 36, 782.

4. G. Neubauer and M. Mann, Anal. Chem., 1999, 71, 235.

5. A. Schlosser, R. Pipkorn, D. Bossemeyer, and W. D. Lehmann, Anal. Chem., 2001, 73, 170.

6. L. Andersson and J. Porath, Anal. Biochem., 1986, 154, 250.

7. G. Muszynska, G. Dobrowolska, A. Medin, P. Ekman, and J. O. Porath, J. Chromatogr., 1992, 604, 19.

8. P. Cao and J. T. Stults, J. Chromatogr. A, 1999, 853, 225.

9. S. Li and C. Dass, Anal. Biochem., 1999, 270, 9.

10. M. C. Posewitz and P. Tempst, Anal. Chem., 1999, 71, 2883.

11. M. S. Kalo and E. B. Pasquale, Biochemistry, 1999, 38, 14396.

12. A. Watty, G. Neubauer, M. Dreger, M. Zimmer, M. Wilm, and S. J. Burden, Proc. Natl. Acad. Sci. USA, 2000, 97, 4585 .

13. K. Janek, H. Wenschuh, M. Bienert, and E. Krause, Rapid Commun. Mass Spectrom., 2001, 15, 1593.

14. B. T. Chait, R. Wang, R. C. Beavis, and S. B. H. Kent, Science, 1993, 262, 89.

15. A. S. Inglis, Anal. Biochem., 1991, 195, 183.

16. A. Tsugita, M. Kamo, K. Takamoto, and K. Satake, J. Protein Chem., 1994, 13, 476.

17. D. H. Patterson, G. E. Tarr, F. E. Regnier, and S. A. Martin, Anal. Chem., 1995, 67, 3971.

18. C. J. Aldrich, A. DeCloux, A. S. Woods, R. J. Cotter, M. J. Soloski, and J. Forman, Cell, 1994, 79, 649.

19. A. S. Woods, A. Y. C. Huang, R. J. Cotter, G. R. Pasternack, D. M. Pardoll, and E. M. Jaffee, Anal. Biochem., 1995, 226, 15.

20. P. F. Murray, P. Hammerschmidt, A. Samela, and S. Passeron, Int. J. Biochem. Cell Biol., 1996, 28, 451. 